\title{
Performance Assessment of Ammonia-Water Based Power and Refrigeration Cogeneration Cycle
}

\author{
Kyoung Hoon Kim, Giman Kim, and Chul Ho Han
}

\begin{abstract}
Recently the concept of combined power and cooling cycles using ammonia-water mixture as the working fluid has attracted much attention, since such systems may offer a reasonable arrangement of energy and exergy flow. In this work thermodynamic performance analysis of combined thermal power and cooling cogeneration cycle using ammonia-water mixture as the working fluid is carried out for efficient use of low-grade heat sources. The cycle is a combination of Rankine cycle and absorption refrigeration cycle, and is investigated parametrically for the purpose of extracting the maximum utilization from a given heat source. A special attention is paid to the effects of important system parameters including turbine inlet pressure, ammonia concentration, and absorber temperature on the performance characteristics of the cycle. Results show that thermodynamic performances of the system are sensitively influenced by system parameters.
\end{abstract}

Index Terms-Ammonia-water mixture, power and cooling, cogeneration, low-grade heat source.

\section{INTRODUCTION}

Binary mixtures exhibit variable boiling temperature during the boiling process, which make them more appropriate to finite heat sources. The temperature difference between the heat source and the working fluid remains small to allow for a good thermal match resulting in irreversibility during the heat addition process. The particular use of ammonia in the binary mixture with water possesses several merits other that the fact that the ammonia is a relatively inexpensive and environmentally safe substance. Ammonia and water have the similar molecular weights and thus, traditional design of steam turbines can be used in the ammonia-water power cycles only with minor modifications. Also, the boiling point of ammonia is substantially lower than that of water, which makes it practically useful to utilize the low-temperature waste heat in the power generation systems [1]-[3]. The energy converting systems using ammonia-water have been intensively investigated during past twenty years [4]-[18]. Combined power and refrigeration have been explored for improving the overall energy conversion efficiency and decreasing the cost of energy per unit capital expense [19]-[23].

A combined thermal power and cooling cycle using ammonia-water as working fluid was proposed and is now called as Goswami cycle [24]. The proposed cycle combines

Manuscript received December 5, 2012; revised February 5, 2013.

The authors are with the Department of Mechanical Engineering, Kumoh National Institute of Technology, Gumi, Gyeongbuk 730-701, Korea (e-mail: \{khkim, giman, chhan\}@ kumoh.ac.kr). a Rankine cycle and an absorption refrigeration cycle, and use very high concentration ammonia vapor in the turbine which can be expanded to a very low temperature in the turbine without condensation. Tamm et al. [25] investigate the proposed cycle both theoretically and experimentally and demonstrate the feasibility of the cycle. Vijayaraghavan and Goswami [26] investigate the propose cycle by optimizing the cycle configuration for maximum resource utilization efficiency (RUE) based on an exergy analysis. Martin and Goswami [27] show that for the combined cycle a compromise exists between cooling and work production, and nearly equal amounts of work are compromised for combined operation. Wang et al. [28] carry out parameter optimization by means of generic algorithm to reach the maximum exergy efficiency. Kim and Han [29] investigate effects of ammonia concentration on the thermodynamic performance of the power and cooling cogeneration cycle using ammonia-water mixture. Pouraghie et al. [30] carry out the thermodynamic performance optimization of the combined power/cooling cycle.

In this work a combined power and cooling cogeneration cycle using ammonia-water mixture as the working fluid, proposed by Goswami and coworkers, is considered for the efficient conversion of low-grade heat source. The thermodynamic performance of the cycle is investigated parametrically by varying important system parameters such as turbine inlet pressure, ammonia concentration, and absorber temperature.

\section{SYSTEM ANALYSIS}

The thermodynamic properties of ammonia-water mixture are computed using the method of Gibbs free energy which was first introduced by Xu and Goswami [31]. However, in this work, the equilibrium conditions are determined by equating the chemical potentials of each phase for each element [3].

$$
\begin{gathered}
\mu_{a}^{L}=\left(\frac{\partial G_{m}^{L}}{\partial N_{a}}\right)_{T, P, N_{w}}=\left(\frac{\partial G_{m}^{g}}{\partial N_{a}}\right)_{T, P, N_{w}}=\mu_{a}^{g} \\
\mu_{w}^{L}=\left(\frac{\partial G_{m}^{L}}{\partial N_{w}}\right)_{T, P, N_{a}}=\left(\frac{\partial G_{m}^{g}}{\partial N_{w}}\right)_{T, P, N_{a}}=\mu_{w}^{g}
\end{gathered}
$$

Here, $N_{\mathrm{a}}$ and $N_{\mathrm{w}}$ are numbers of moles of ammonia, water, and the mixture, respectively, and the Gibbs free energy of $G_{\mathrm{m}}$ for liquid or gas phase is denoted as 


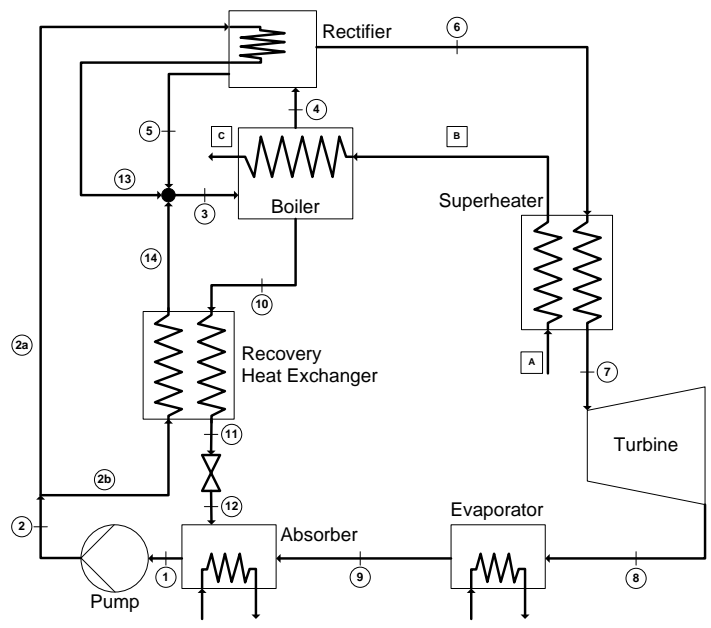

Fig. 1. Schematic diagram of the system.

$$
G_{m}=N_{a}\left[G_{a}+R T \ln x\right]+N_{w}\left[G_{w}+R T \ln (1-x)\right]+N G^{E}
$$

The cycle is a cogeneration cycle which combines the Rankine cycle and the absorption cycle, and can produce both power and refrigeration simultaneously with a heat source. The schematic diagram of the system is shown in Fig. 1. An ammonia-water mixture leaves the absorber as a saturated solution at a basic ammonia mass concentration $x_{\mathrm{b}}$ and temperature $T_{\mathrm{L}}$ (state 1 ). It is pumped to a turbine inlet pressure which is the system high pressure, $P_{\mathrm{H}}$ (state 2 ). It is then split into two streams of stream $2 \mathrm{a}$ and stream $2 \mathrm{~b}$. Stream $2 \mathrm{a}$ is preheated through the rectifier by the rejected heat in this device (state 13 ). Stream $2 b$ recovers heat from the returning weak ammonia liquid solution in the recovery heat- exchanger before entering the boiler (state 14). As the boiler operation temperature $T_{\mathrm{b}}$ lies between the bubble and dew point temperature of the mixture at the system pressure, the basic solution is partially boiled to produce a two-phase mixture of a liquid with relatively low concentration (state 10) and a vapor (state 4) with a high concentration of ammonia.

The two-phase-mixture is separated, and the low concentration liquid transfers heat to the high concentration stream before it is throttled to the system low pressure and sprayed into the absorber. The rectifier cools the saturated ammonia vapor (state 6) to condense out remaining water. Heat can be added in the super heater as the vapor (state 7) proceeds to the turbine. The turbine extracts energy from the high-pressure vapor as it is expanded to the system low pressure (state 8 ). The expanded vapor has still the potential for refrigeration due to the low boiling point of ammonia. The vapor is finally absorbed back into the liquid giving off heat (state 9) and rejoins the weak in the absorber, where with heat rejection the basic solution is regenerated. In this work it is assumed that pressure drop and heat loss of the systems are negligible and the minimum temperature difference between the hot and cold streams in the heat exchanger is operated at a prescribed pinch point, $\Delta T_{\mathrm{PP}}$ [29]. Then heat addition at boiler and super heater, $q_{\mathrm{ab}}$ and $q_{\mathrm{sh}}$ are obtained as

$$
\begin{gathered}
q_{b}=m_{4} h_{4}+m_{10} h_{10}-m_{3} h_{3} \\
q_{s h}=m_{6}\left(h_{7}-h_{6}\right)
\end{gathered}
$$

where $h$ denotes the specific enthalpy and $m$ the mass flow rate at each position when the mass flow rate at pump is 1 $\mathrm{kg} / \mathrm{s}$. Cooling capacity and system net work, $q_{\mathrm{e}}$ and $w_{\text {net }}$ are evaluated as

$$
\begin{gathered}
q_{e}=m_{6}\left(h_{9}-h_{8}\right) \\
w_{n e t}=w_{t}-w_{p}=m_{6}\left(h_{7}-h_{8}\right)-m_{1}\left(h_{2}-h_{1}\right)
\end{gathered}
$$

where $w_{\mathrm{t}}$ and $w_{\mathrm{p}}$ denote turbine and pump work, respectively. Then total heat input, utilization of the system and thermal efficiency, $q_{\text {in }}, W_{\text {tot }}$ and $\eta_{\text {th }}$ are obtained as follows.

$$
\begin{gathered}
q_{\text {in }}=q_{b}+q_{s h} \\
w_{\text {tot }}=w_{\text {net }}+q_{e} \\
\eta_{t h}=w_{t o t} / q_{\text {in }}
\end{gathered}
$$

\section{RESULTS AND DISCUSSIONS}

The combined cycle considered in this paper produces power and refrigeration simultaneously in a loop and requires less equipment. The basic operation data are as follows; absorber temperature, $T_{\mathrm{L}}=8{ }^{\circ} \mathrm{C}$, boiler temperature, $T_{\mathrm{b}}=130$ ${ }^{\circ} \mathrm{C}$, rectifier temperature, $T_{\text {rec }}=90{ }^{\circ} \mathrm{C}$, turbine inlet temperature, $T_{\mathrm{H}}=140{ }^{\circ} \mathrm{C}$, turbine inlet pressure, $P_{\mathrm{H}}=25 \mathrm{bar}$, pinch point, $\Delta T_{\mathrm{PP}}=5{ }^{\circ} \mathrm{C}$, isentropic efficiencies of pump and turbine, $\eta_{\mathrm{p}}=80 \%$ and $\eta_{\mathrm{t}}=85 \%$, and basic ammonia mass concentration, $x_{\mathrm{b}}=55 \%$. The system low pressure is determined from bubble point condition for the given temperature and ammonia concentration at state 1 . In this work, the mass flow rate at pump is assume to be $1 \mathrm{~kg} / \mathrm{s}$, therefore heat transfers and works at various components such as $q_{\mathrm{b}}, q_{\mathrm{sh}}, q_{\mathrm{in}}, q_{\mathrm{e}}, w_{\text {net }}$, and $w_{\text {tot }}$ denote quantities per unit mass of working fluid at pump.

For various ammonia concentrations, Fig. 2 shows effects of turbine inlet pressure on boiler heat addition, $q_{\mathrm{b}}$, and total heat addition, $q_{\text {in }}$, which is sum of the boiler and superheater heat additions, namely $q_{\text {in }}=q_{\mathrm{b}}+q_{\mathrm{sh}}$ as is seen in Eq. (8). For a fixed ammonia concentration, there are low and upper limits of turbine inlet pressure, since heat addition at superheater decreases to zero when the pressure increases to the upper limit, while cooling capacity or net work decreases to zero when the pressure decreases to the lower limit. Operation of the system for values of the turbine inlet pressure outside the limits would be inadequate, since the heat addition at superheater or cooling capacity would be negative for the values. For a fixed ammonia concentration, both the boiler and total heat additions decrease with increasing turbine inlet pressure, since heat of vaporization decreases with increasing turbine inlet pressure. For a fixed turbine inlet pressure, both the boiler and total heat additions increase with ammonia concentration.

Fig. 3 illustrates that super-heater heat addition $q_{\text {sh }}$ decreases with increasing turbine inlet pressure for a given ammonia concentration superheater heat addition. However, as turbine inlet pressure increases, cooling capacity at absorber $q_{\mathrm{e}}$ increases first and reaches a maximum value and 
the decreases, so it has an optimal value with respect to turbine inlet pressure. For a fixed turbine inlet pressure, the superheater heat addition increases with turbine inlet pressure, but the cooling capacity has an optimum value with respect to turbine inlet pressure.

Fig. 4 shows that for a given ammonia concentration, heat transfer at heat exchanger, $q_{\mathrm{he}}$ decreases but heat transfer at rectifier, $q_{\text {rec }}$ increases as turbine inlet pressure increases. However, for a fixed turbine inlet pressure, heat transfer at heat exchanger increases but heat transfer at rectifier decreases as ammonia concentration increases. It can be seen also from the figure that heat transfer at heat exchanger is always greater than that at rectifier.

Fig. 5 illustrates that for a given ammonia concentration, net work, $w_{\text {net }}$ decreases with increasing turbine inlet pressure, but total utilization, $w_{\text {tot }}$ may have an optimum value with respect to turbine inlet pressure. Here, total utilization work is defined as the sum of net work and cooling capacity. However, both the net work and total utilization work increase with ammonia concentration for a fixed turbine inlet pressure.

Thermal efficiency of the system is defined as the ratio of total utilization work to heat addition to the system. Fig. 6 shows that thermal efficiency has an optimum value with respect to both the turbine inlet pressure and ammonia concentration.

For a fixed value of ammonia concentration of 55\%, Figs. 7-8 illustrate the effects of turbine inlet pressure and absorber temperature on the thermodynamic performance of the system. Fig. 7 shows that for a fixed turbine inlet pressure, both the net work and total utilization work increase with decreasing absorber temperature, since as the absorber temperature decreases, the corresponding evaporating pressure also decreases, which leads the pressure ratio of the turbine higher, therefore the turbine work increases consequently. It is worthy to note that lower limit of turbine inlet pressure for adequate operation decreases as the absorber temperature increases, which can be seen from the figure. Fig. 8 shows that thermal efficiency increases with decreasing absorber temperature, while it has on optimum value with respect to turbine inlet pressure.

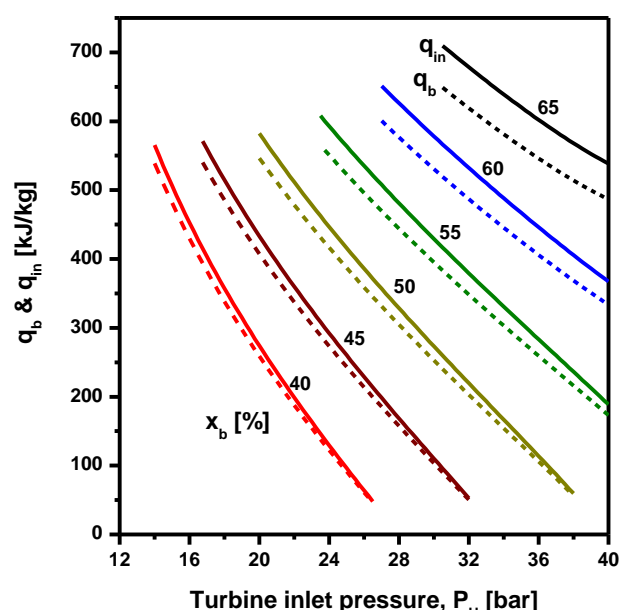

Fig. 2. Effects of turbine inlet pressure on boiler and total heat additions for various ammonia concentrations.

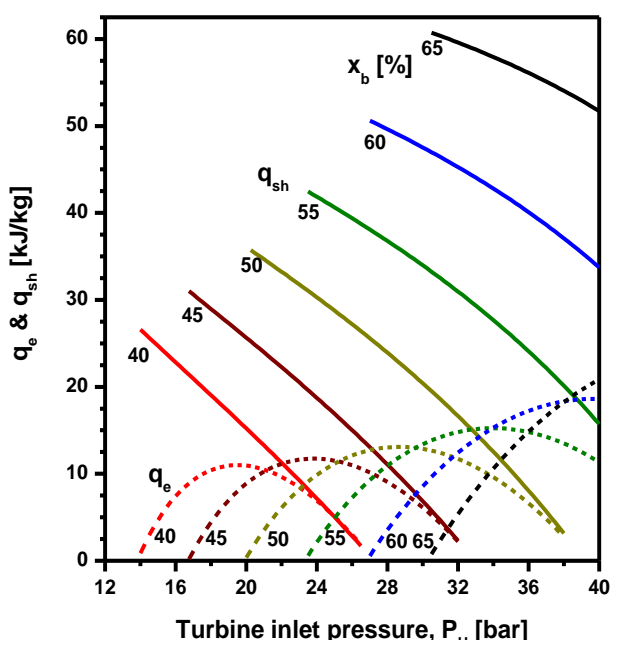

Fig. 3. Effects of turbine inlet pressure on cooling capacity and superheater heat addition for various ammonia concentrations.

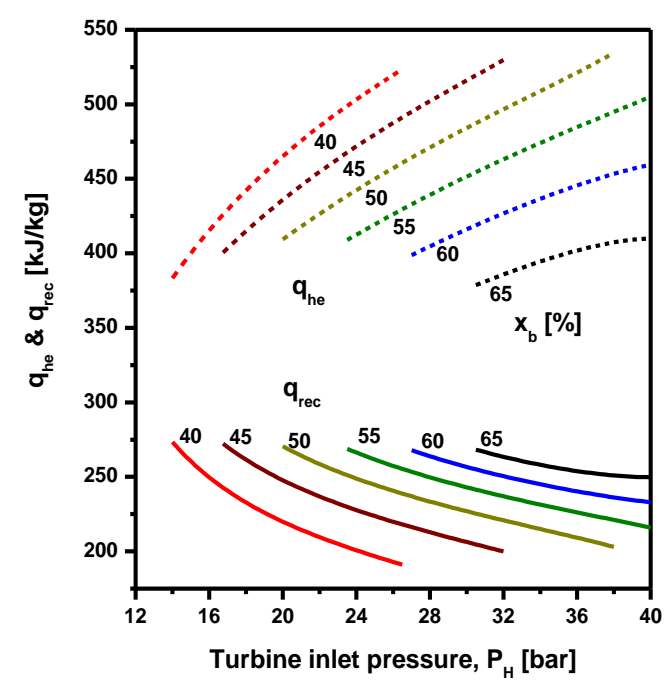

Fig. 4. Effects of turbine inlet pressure on heat transfers at heat exchanger and rectifier for various ammonia concentrations.

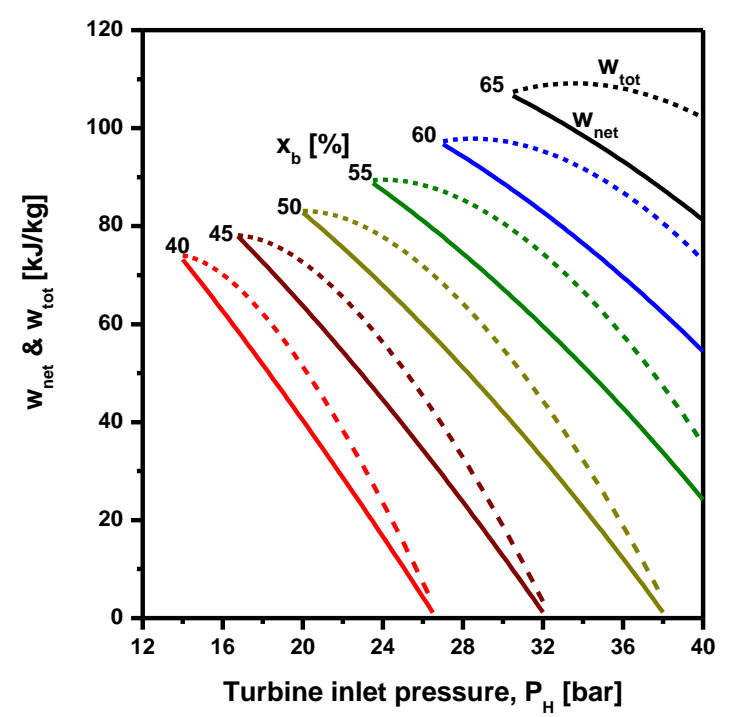

Fig. 5. Effects of turbine inlet pressure on the net and total works for various ammonia concentrations. 


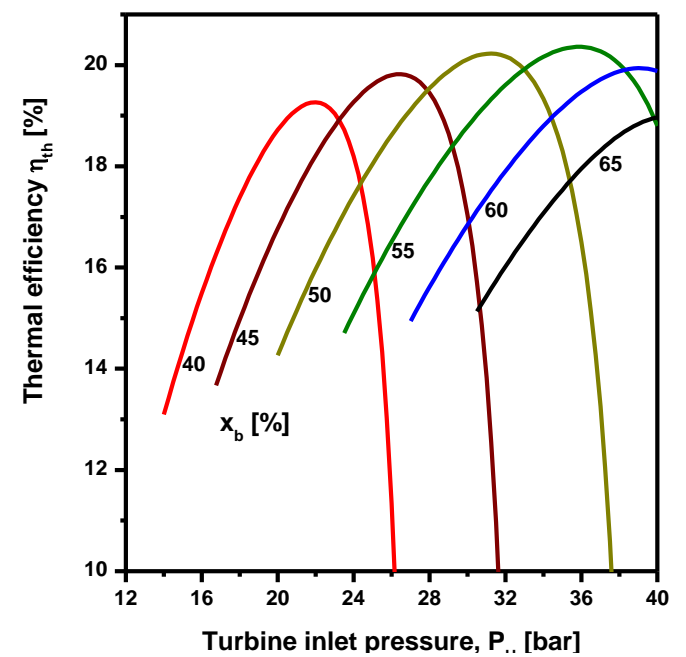

Fig. 6. Effects of turbine inlet pressure on thermal efficiency for various ammonia concentrations.

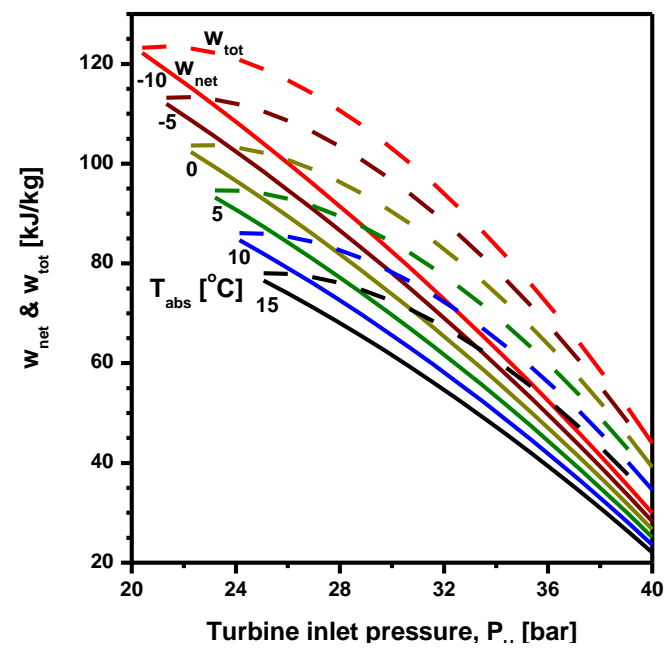

Fig. 7. Effects of turbine inlet pressure on the net and total works for various absorber temperatures.

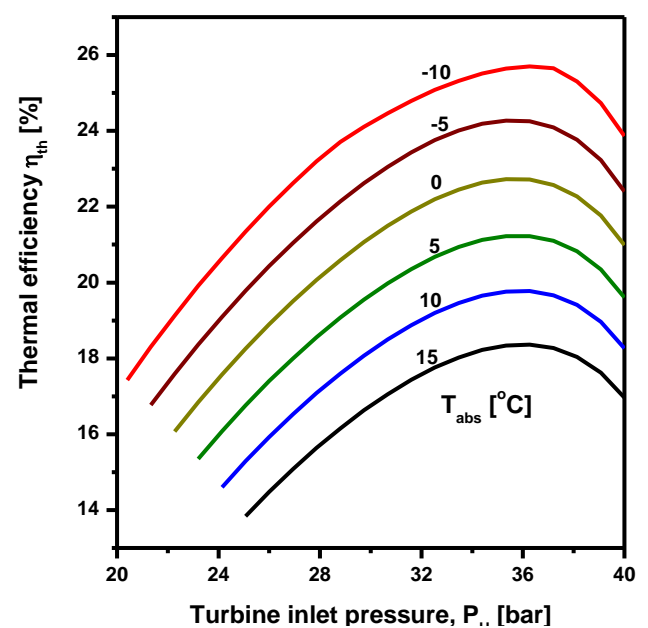

Fig. 8. Effects of turbine inlet pressure on the thermal efficiency for various absorber temperatures.

\section{CONCLUSIONS}

In this paper the thermodynamic performance of the combined power and refrigeration cycle is studied for efficient use of low-grade heat sources, which combines the Rankine and absorption refrigeration cycle using ammonia-water mixture as the working fluid. Parametric analysis is carried out to investigate the effects of several system parameters on the system performance. Special attention is focused on the effects of the turbine inlet pressure and absorber temperature. Results show that there exist lower and upper limits of the turbine inlet pressure, since the heat input at the superheater decreases to zero as the pressure becomes too large, while the specific cooling decreases to zero as the pressure becomes too low. The lower limit decreases with increasing absorber temperature. Results also show that network decreases with increasing pressure, however, specific cooling capacity, total utilization work, and thermal efficiency has an optimum value with respect to the turbine inlet pressure.

\section{ACKNOWLEDGMENT}

This paper was supported by Research Fund, Kumoh National Institute of Technology.

\section{REFERENCES}

[1] R. V. Padilla, G. Dimirkaya, D. Y. Goswami, E. Stefanokos, and M. M Rahman, "Analysis of power and cooling cogeneration using ammonia-water mixture," Energy, vol. 35, pp. 4649-4657, 2010.

[2] K. H. Kim, "Thermal analysis of a combined absorption cycle of cogeneration of power and cooling for use of low temperature source," SAREK, vol. 23, pp. 413-420, 2011.

[3] K. H. Kim, C. H. Han, and K. Kim, "Effects of ammonia concentration on the thermodynamic performances of ammonia-water based power cycles," Thermochimica Acta, vol. 530, pp. 7-16, 2012.

[4] V. A. Prisyazhniuk, "Alternative trends in development of thermal power plants,” App. Therm. Eng., vol. 28, pp. 190-194, 2008.

[5] B. Kiani, A. Akisawa, and T. Kashiwagi, "Thermodynamic analysis of load-leveling hyper energy converting and utilization," Energy, vol. 33, pp. 400-409, 2008.

[6] S. Ogriseck, "Integration of kalina cycle in a combined heat and power plant, a case study," App. Therm. Eng., vol. 29, pp. 2843-2848, 2009.

[7] J. Wang, Y. Dai, T. Zhang, and S. Ma, "Parametric analysis for a new combined power-and ejector-absorption refrigeration cycle," Energy, vol. 34, pp. 1587-1593, 2009.

[8] P. A. Lolos and E. D. Rogdakis, "A Kalina power cycle driven by renewable energy sources,” Energy, vol. 34, pp. 457-464, 2009.

[9] X. Shi and D. A. Che, "A combined power cycle utilizing low-temperature waste heat and LNG cold energy," Energy Conv. Mgmt., vol. 50, pp. 567-575, 2009.

[10] O. Aslan, "Exergoeconomic evaluation of electricity generation by the medium temperature geothermal resources using Kalina cycle: Simav case study," Int. J. Therm. Sci., vol. 49, pp. 1866-1873, 2010.

[11] P. Bombarda, C. M. Invernizzi, and C. A. Pietra, "A thermodynamic comparison between Kalina and ORC cycles," App. Therm. Eng., vol. 30, pp. 212-219, 2010.

[12] W. R. Wagar, C. Zamfirescu, and I. Dincer, "Thermodynamic performance assessment of an ammonia-water Rankine cycle for power and heat production," Energy Conv. Mgmt., vol. 51, pp. 2501-2509, 2010.

[13] P. Roy, M. Desilets, N. Galanis, H. Nesreddine, and E. Cayer, "Thermodynamic analysis of a power cycle using a low-temperature source and a binary $\mathrm{NH}_{3}-\mathrm{H}_{2} \mathrm{O}$ mixture as working fluid," Int. J. Therm. Sci., vol. 49, pp. 48-58, 2010.

[14] T. Q. Nguyen, J. D. Slawnwhite, and G. Boulama, "Power generation from residual heat," Energy Conv. Mgmt., vol. 51, pp. 2220-2229, 2010.

[15] S. Ma, J. Wang, Z. Yan, Y. Dai, and B. Lu, "Thermodynamic analysis of a new combined cooling, heat and power system driven by solid oxide fuel cell based on ammonia-water mixture," J. Power Sources, vol. 196, pp. 8463-8471, 2011. 
[16] O. Aslan, "Power generation from medium temperature geothermal resources: ANN-based optimization of Kalina cycle system-34," Energy, vol. 36, pp. 2528-2534, 2011.

[17] N. Galanis, E. Cayer, P. Roy, E. S. Denis, and M. Desilets, "Electricity generation from low temperature sources," J. App. Fluid Mech., vol. 2, pp. 55-67, 2009.

[18] A. B. Little and S. Garimella, "Comparative assessment of alternative cycles for waste heat recovery and upgrade," Energy, vol. 36, pp. 4492-4504, 2011.

[19] K. Takeshita, Y. Amano, and T. Hashizume, "Experimental study of advance cogeneration system with ammonia-water mixture cycles at bottoming," Energy, vol. 30, pp. 247-260, 2005.

[20] D. Zheng, B. Chen, Y. Qi, and H. Jin, "Thermodynamic analysis of a novel absorption power/cooling combined-cycle," App. Energy, vol. 83, pp. 311-323, 2006

[21] O. M. Al-Hawaj and H. A. Al-Mutairi, "A combined power cycle with absorption air conditioning," Energy, vol. 32, pp. 971-982, 2007.

[22] N. Zhang and N. Lior, "Methodology for thermal design of novel combined refrigeration/power binary fluid systems," Int. $J$. Refrigeration, vol. 30, pp. 1072-1085, 2007.

[23] M. Liu and N. Zhang, "Proposal and analysis of a novel ammonia-water cycle for power and refrigeration cogeneration," Energy, vol. 32, pp. 961-970, 2007.

[24] F. Xu, Y. Goswami, and S. S. Bhagwat, "A combined power/cooling cycle," Energy, vol. 25, pp. 233-246, 2000.

[25] G. Tamm, D. Y. Goswami, S. Lu, and A. A. Hasan, "Theoretical and experimental investigation of an ammonia-water power and refrigeration thermodynamic cycle," Solar Energy, vol. 76, pp. 217-228, 2004.

[26] S. Vijayaraghavan and D. Y. Goswami, "A combined power and cooling cycle modified to improve resource utilization efficiency using a distillation stage," Energy, vol. 31, pp. 1177-1196, 2006.

[27] C. Martin and D. Y. Goswami, "Effectiveness of cooling production with a combined power and cooling thermodynamic cycle," App. Therm. Eng., vol. 26, pp. 576-582, 2006.

[28] J. Wang, Y. Dai, and L. Gao, "Parametric analysis and optimization for a combined power and refrigeration cycle," App. Energy, vol. 85, pp. 1071-1085, 2008.
[29] K. H. Kim and C. H. Han, "Thermodynamic performance of ammonia-water cycle for power and refrigeration cogeneration," Appl. Math. Inf. Sci., in press, 2012.

[30] M. Pouraghaie, S. M. Atashkari, S. M Besarati, and N. N. Zadeh, "Thermodynamic performance optimization of a combined power/cooling cycle," Energy Convs. Mgmt., vol. 51, pp. 204-211, 2010.

[31] F. Xu and D. Y. Goswami, "Thermodynamic properties of ammoniawater mixtures for power-cycle applications," Energy, vol. 24, pp. 525-536, 1999.

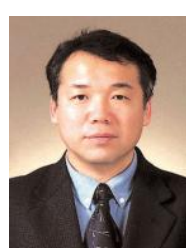

Kyoung Hoon Kim received the Ph.D. degree in mechanical engineering from Korea Advanced Institute of Science and Technology (KAIST). He is currently a Professor with the Department of Mechanical Engineering at Kumoh National Institute of Technology, Korea. His research interests are in the areas of modeling and design of energy systems.

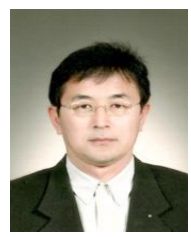

Giman Kim received the Ph.D. degree in Engineering Science and Mechanics from The Pennsylvania State University. $\mathrm{He}$ is currently a Professor with the Department of Mechanical System Engineering at Kumoh National Institute of Technology, Korea. His research interests are in the areas of modeling and design of energy systems and structural vibrations.

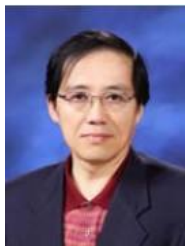

Chul Ho Han received the Ph.D. degree in production engineering from Korea Advanced Institute of Science and Technology (KAIST). He is currently a Professor with the Department of Intelligent Mechanical Engineering at Kumoh National Institute of Technology, Korea. His research interests are in the areas of reliability engineering of systems and evaluation of formability test. 